\title{
ARTigOS
}

Maria Lucia Viana Cardoso ${ }^{1}$

Paulo Delgado ${ }^{2}$

\section{IMPACTO DO PRONATEC PRISIONAL NA TRAJETÓRIA DE VIDA DE APENADOS DO PRESÍDIO ESTADUAL DE JÚLIO DE CASTILHOS, RS, BRASIL}

\author{
IMPACT OF PRONATEC PRISIONAL ON THE LIFE TRAJECTORY OF THE \\ PRISONERS OF THE JULIO DE CASTILHOS STATE PRISON, RS, BRAZIL
}

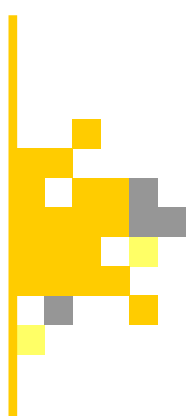

\section{RESUMO:}

A assistência educacional para indivíduos privados de liberdade é um dos direitos garantidos constitucionalmente e regrados pela Lei de Execução Penal, que viabiliza remição de pena e, sobretudo, cria condições de ressocialização. O presente estudo propõe analisar a realidade de um grupo de apenados do Presídio Estadual de Júlio de Castilhos que concluíram cursos do Pronatec Prisional e assim, obter subsídios para averiguar se a ação foi exitosa e se de fato colaborou para a formação e ressocialização destes egressos. A investigação partiu de um estudo de caso cuja metodologia qualiquantitativa baseou-se em entrevistas e aplicação de questionários, retratando o ponto-devista dos vários sujeitos envolvidos. Da referida investigação foi possível verificar o impacto das ações realizadas, detectar alguns pontos a serem aprimorados e concluir que as políticas públicas vinculadas à educação em ambientes prisionais são, de fato, imprescindíveis para que indivíduos privados de liberdade estejam preparados para um recomeço em sociedade.

PALAVRAS-CHAVE: Pronatec; Prisional; Educação profissional; Remição da pena; Ressocialização

\section{ABSTRACT:}

Educational assistance for individuals incarcerated is one of the constitutionally guaranteed rights ruled by the Criminal Enforcement Law, which makes it possible for the reduction of punishment and, above all, creates conditions of resocialization. This present study proposes to analyze the reality of a group of prisoners in the State Prison of Júlio de Castilhos, who have concluded their Pronatec Prisional Courses and thus, obtain subsidies to verify whether the action was successful and if in fact collaborated for the formation and resocialization of these graduates. The research was based on a case study whose qualitative-quantitative methodology using interviews and questionnaires, portraying the point of view of the various subjects involved. From this investigation it was possible to verify the impact of the actions carried out, to detect some points that need to be improved upon and to conclude that public policies that are linked to education inside prisons are, in fact, essential for the incarcerated individuals to be prepared for a new beginning in society.

KEYWORDS: Pronatec; Prison; Professional education; Remission of penalty; Resocialization

\footnotetext{
${ }^{1}$ Bacharel em Ciências Jurídicas e Sociais, Especialista em Direito Processual e Mestra em Educação pelo Politécnico do Porto, Portugal— malu.cardoso@iffarroupilha.edu.br, iD https://orcid.org/0000-0003-4893-5422

${ }^{2}$ inED - Centro de Investigação e Inovação em Educação, Escola Superior de Educação do Politécnico do Porto, Portugal pdelgado@ese.ipp.pt, (iD) http://orcid.org/0000-0001-6977-8214
} 


\section{A POLÍTICA PARA A EDUCAÇÃO EM AMBIENTES PRISIONAIS}

A ressocialização de apenados é uma demanda premente e que tem como finalidade primordial viabilizar aos presos as mínimas condições para recomeçarem suas vidas, quando em liberdade. Neste contexto, percebe-se a real importância de ações inclusivas, voltadas à educação e ao trabalho, propiciadas pela administração do sistema carcerário, com vistas à redução das penas e preparo dos apenados para sua reintegração em sociedade.

Trata-se de uma temática "invisível" aos olhos de grande parte da população, o que se constata ao auferir o quantitativo reduzido de estudos na área, o pouco interesse social e a realidade percebida, fatores que por si só já corroboram a necessidade de se debater o papel da educação na política de execução penal de forma mais aprofundada, quer seja pelo meio acadêmico, quer seja pelos órgãos governamentais e a sociedade.

O presente artigo estuda a realidade de um grupo de apenados que tiveram a oportunidade de se qualificar durante o cumprimento de suas penas, por meio de um programa federal de educação profissional, dentro de uma perspectiva de permitir a remição de pena e facilitar a ressocialização dos mesmos.

A pesquisa se deteve na situação dos alunos matriculados nos cursos do Pronatec Prisional ofertados pelo Instituto Federal de Educação, Ciência e Tecnologia Farroupilha (IFFar) - Campus Júlio de Castilhos nas dependências do Presídio deste município.

\subsection{ASPECTOS LEGAIS}

Com a promulgação da Lei no 7.210 , denominada Lei de Execução Penal - LEP (Brasil, 1984), a execução das penas e medidas de segurança passou a ser regulamentada no Brasil, objetivando uniformizar o tratamento dado aos apenados. Influenciada por tratados e convenções internacionais, foi uma lei considerada avançada, vindo a se destacar fora do país, por reconhecer o preso como sujeito de direito, detentor de direitos e obrigações.

Em decorrência de uma condenação, o preso perde o direito à liberdade durante a execução da pena, mas permanece com os demais direitos garantidos, nos termos do art. 3ㅇ e 40 da LEP, assim como lhe são imputados deveres e obrigações (arts. 38 e 39), sempre com vistas à posterior reintegração à sociedade. Em contrapartida, atendendo ao que preceitua o art. 11 da LEP, o Estado deve prover aos presos, sejam eles condenados ou provisórios, assistência material, à saúde, jurídica, educacional, social e religiosa.

Neste sentido, um dos benefícios conferidos aos presos sob a égide da Lei de Execução Penal consiste na possibilidade de remição da pena, originalmente com base nos dias trabalhados dentro do cárcere. Trabalho este que deveria ser propiciado no ambiente prisional, mas que na prática não se estende a todos, quer por falta de oportunidade (oferta de trabalho inexistente ou insuficiente para atender à totalidade dos interessados), quer pelo desinteresse do preso.

Em 2011 a Lei no 12.433 ampliou o alcance do art. 126 (que previa remição pelo trabalho) ao possibilitar, também, a redução de 1 (um) dia de pena a cada 12 (doze) horas de frequência escolar:

\footnotetext{
Art. 126. O condenado que cumpre a pena em regime fechado ou semiaberto poderá remir, por trabalho ou por estudo, parte do tempo de execução da pena.

$\S 1$ - A contagem de tempo referida no caput será feita à razão de:

I - 1 (um) dia de pena a cada 12 (doze) horas de frequência escolar - atividade de ensino fundamental, médio, inclusive profissionalizante, ou superior, ou ainda de requalificação profissional divididas, no mínimo, em 3 (três) dias [...] (Brasil, 2011a)
}

Dentro desta possibilidade de remição, pode o apenado (mesmo no regime aberto, em liberdade condicional ou em prisão cautelar) estudar 
em cursos presenciais ou à distância e, conforme dispõe o § 50 do referido artigo, uma vez concluída uma modalidade de ensino (seja ela do fundamental, médio ou superior) dentro do prazo da execução da pena (ou do tempo de prova) e desde que sendo certificado por órgão de ensino competente, terá o acréscimo de $1 / 3$ no tempo a ser remido.

Seguindo esta lógica, vem à tona a questão objeto do presente estudo, com a possibilidade de verificar, in loco, se há uma relação direta entre a remição da pena e a ressocialização, considerando que a oportunidade de estudar e/ou trabalhar durante a execução da pena não somente abrevia o tempo no cárcere, mas também prepara o preso para o momento da ressocialização, do recomeço em um mundo atrás das grades.

\subsection{ACESSO À EdUCAÇÃO}

O direito à educação está previsto constitucionalmente dentre o rol de direitos sociais elencados na Lei Magna, visando o pleno desenvolvimento da pessoa, o seu preparo para o exercício da cidadania e a sua qualificação para o trabalho. (Brasil, 1988).

A garantia do direito à Educação destaca-se como fundamental uma vez que a cidadania se faz via Escola e também é na Escola que se aprendem deveres e direitos que nos remetem à condição de indivíduos aptos a exercer cidadania de maneira clara e consciente. Cidadãos bem preparados são futuros elementos de um povo que investe e tem a educação como primeiro propósito.

Neste sentido, atendendo ao que dispõe a Carta Magna, em 20 de dezembro de 1996 foi promulgada a Lei no 9.394, a denominada Lei de Diretrizes e Bases da Educação Nacional - LDB, que de início, já vincula a proposta à formação para o mundo do trabalho, pois determina no caput do artigo 1 que "a educação abrange os processos formativos que se desenvolvem na vida familiar, na convivência humana, no trabalho (...)" e reforça, no parágrafo $2 \circ$, que "a educação escolar deverá vincular-se ao mundo do trabalho e à prática social” (Brasil, 1996).
Especificamente sobre a educação profissionalizante, há que se considerar que a Educação é a base para formação do cidadão e cria condições de empregabilidade no mundo do trabalho, e de que sim, cabe ao Estado proporcionar este direito a todos, razão pela qual existe previsão constitucional da relação da educação com o mundo do trabalho (art. 214, CF/88).

Dentre as modalidades de ensino previstas na LDB, está a Educação Profissional de nível médio, referenciada nos artigos 36 e seguintes, os quais foram acrescidos pela Lei no 11.741. Mas é no Capítulo III, artigo 39, cuja redação também foi dada pela lei supracitada, que incluiu-se a Educação Profissional em todos os seus níveis, proporcionando, desta forma, a verticalização do ensino e viabilizando a implantação de itinerários formativos, onde o aluno consegue iniciar no curso técnico e seguir até a pós-graduação stricto sensu (Brasil, 2008a).

Nas palavras de Araújo e Borges (2000), há que se considerar que na sociedade do conhecimento, há um novo perfil de trabalhador "que só pode ser alcançado com um sistema educacional renovado, capaz de preparar o trabalhador não apenas para lidar com novas tecnologias, mas para exercer com plenitude a sua capacidade de crítica, de reflexão sobre a sociedade em que vive (p.16).

Fato importante para o fortalecimento da educação profissional ocorreu com o advento da Lei no 11.892 (Brasil, 2008b), de 29 de dezembro de 2008 que instituiu a Rede Federal de Educação Profissional, Científica e Tecnológica contemplando a criação dos Institutos Federais de Educação, Ciência e Tecnologia, compostos pelas antigas Escolas Técnicas Federais (com cerca de 100 anos de existência) e a implantação de inúmeros novos campi em todo o território brasileiro.

Neste atual contexto, visando atender as demandas de um mercado que carece de mão de obra especializada, de um lado, e de jovens sem formação que precisam de emprego, do outro, o Governo Federal tem adotado várias políticas públicas educacionais, algumas com maior impacto 
na formação para o mundo do trabalho, a exemplo da Rede E-Tec Brasil (Educação Técnica à distância), Brasil Profissionalizante, Rede Certific (Certificação de Saberes), e mais recentemente, o Programa Nacional de Acesso ao Ensino Técnico e Emprego Pronatec.

O Pronatec tem como base legal a Lei $n^{\circ}$ 12.513 (Brasil, 2011b) e foi criado com o intuito de ampliar a oferta de cursos de educação profissional e tecnológica (nas modalidades: Técnico subsequente, Técnico concomitante e de Formação inicial e continuada ou qualificação profissional) e encaminhar os estudantes concluintes ao mercado de trabalho.

\subsection{A EduCAÇÃo NO CÁRCERE}

Segundo Julião (2016), a Educação no ambiente prisional pode ter como objetivo "conseguir um resultado útil, tais como ofícios, conhecimentos, compreensão, atitudes sociais e comportamento, que perdurem além da prisão e permitam ao apenado o acesso ao emprego ou a uma capacitação superior, que, sobretudo, propicie mudanças de valores, pautando-se em princípios éticos e morais". (p. 34)

Mas falar em educação neste ambiente requer entender e respeitar as suas especificidades. No entanto, na prática, conforme destaca o referido autor, constatam-se "experiências com propostas pedagógicas descontextualizadas da realidade do sistema prisional. São escolas que por um acaso - estão na prisão" (Julião, 2016, p. 36).

$O$ investimento em educação no âmbito prisional restringe-se ao mínimo exigido por lei, por " $n$ " fatores, aliados ao escasso investimento e à precária estrutura do sistema penitenciário no Brasil. De facto, nem todas as penitenciárias apresentam estrutura condizente para atender às mínimas necessidades assistenciais, especialmente no âmbito educacional, tais como salas de aula em número suficiente, bibliotecas e laboratórios para aulas práticas, etc..
Percebe-se que a situação de estabelecimentos penais de segurança mínima e média se apresenta mais restrita ainda, quer pela infraestrutura, quer pela existência de tantas outras prioridades que também demandam investimento e que acabam deixando a educação em segundo ou terceiro plano. Contudo, o fato de ser uma população carcerária menor ou de menos periculosidade não é justificativa para que o direito à educação no cárcere seja preterida frente às demais garantias e direitos previstos aos sujeitos privados de liberdade.

Em termos estatísticos e como reflexo destas diretrizes educacionais, podemos constatar alguns dados bem relevantes, que confirmam a necessidade de maior atenção para a educação no âmbito prisional: o Ministério da Justiça (2017) publicou o Levantamento Nacional de Informações Penitenciárias, trazendo um panorama em todas as áreas assistenciais. $\mathrm{Na}$ educação, especificamente, podemos constatar que a maioria da população carcerária é relativamente jovem (entre 18 e 35 anos), no entanto, mais da metade (51\%) possui apenas o ensino fundamental incompleto e outros $10 \%$ analfabetos ou alfabetizados sem cursos regulares.

De acordo com o referido levantamento, apenas $12 \%$ da população prisional no Brasil está envolvida em algum tipo de atividade educacional, entre aquelas de ensino escolar e atividades complementares (tais como, remição pelo estudo por meio da leitura, pessoas matriculadas em programas de remição pelo estudo por meio do esporte, videoteca, atividades de lazer e cultura).

No plano nacional, a pauta da educação no cárcere tem sido tratada como política de inclusão e encontra amparo legal em diversas legislações, partindo de um Plano Nacional de Educação - PNE, inicialmente regido pela Lei $\mathrm{n}$ - 10.172, o qual previa a obrigatoriedade de "implantar, em todas as unidades prisionais e nos estabelecimentos que atendam adolescentes e jovens infratores, programas de educação de jovens e adultos de nível fundamental e médio, assim como de formação profissional" (Brasil, 2001). 
Em 2011, perseguindo o propósito de dar efetividade ao direito à assistência educacional prevista na LEP na Seção V, arts. 17 a 21, bem como por conta do art. 83 , §4으, incluído pela Lei $n$ ㅇ 12.245 (Brasil, 2010), o qual prevê instalação de salas de aulas destinadas a cursos do ensino básico e profissionalizante, o Plano Estratégico de Educação no âmbito do Sistema Prisional - PEESP foi instituído a partir da promulgação do Decreto no 7.626 (Brasil, 2011b). Tal plano foi criado para ser administrado, em conjunto, pelos Ministérios da Justiça e da Educação, tendo a finalidade de fomentar, ampliar e qualificar, a oferta educacional nos ambientes prisionais, cujas competências dos partícipes constam elencadas no PEESP, arts. 607\%

Resoluções foram expedidas a fim de dar efetividade ao referido decreto. A Resolução CNE no 4/2016, por exemplo, veio para regular as diretrizes operacionais nacionais para a remição da pena pelo estudo de pessoas privadas de liberdade, com a garantia de oferta de Educação de Jovens e Adultos (EJA), de Educação Profissional Técnica de Nível Médio e os respectivos itinerários formativos, a partir de cursos de qualificação profissional (Ministério da Educação, 2016).

Em relação aos Estados Federativos, a eles incumbe, por meio de suas Secretarias Estaduais de Educação, a responsabilidade de fomentar a política educacional para jovens e adultos em situação de privação de liberdade, passando a ser encarada como política pública na área educacional atrelada às suas particularidades e sua realidade regional.

No Rio Grande do Sul, o órgão responsável pelo sistema penitenciário é a Superintendência dos Serviços Penitenciários do Rio Grande do Sul Susepe que é subordinada à Secretaria da Segurança Pública - SSP. Trata-se do órgão estadual responsável pela execução administrativa das penas privativas de liberdade e das medidas de segurança. No entanto, a oferta educacional nos estabelecimentos prisionais no Rio Grande do Sul está sob a responsabilidade da Secretaria Estadual de Educação - SEDUC, sendo nesta Secretaria que pedagogos e/ou professores envolvidos na educação carcerária estão vinculados.
Para atender ao PEESP, o Setor de Educação Prisional da Susepe trabalha em parceria com a SEDUC na implantação de NEEJA's nas unidades prisionais, e coordena a Suseperelação entre a SEDUC e a unidade prisional onde estiver NEEJA implantado.

De acordo com Departamento de Segurança e Execução Penal da Susepe/RS, a população carcerária gaúcha masculina é predominantemente jovem, onde a faixa etária dos 18 aos 34 anos representa $64 \%$ do total apurado, além disso, quase $60 \%$ são solteiros. Em relação ao grau de instrução, consoante a realidade nacional, os apenados gaúchos, em sua maioria (61,5\%) também apresentam apenas ensino fundamental incompleto, configurando o público mais carente de assistência educativa, foco das políticas públicas inclusivas e do atendimento das diretrizes educacionais. Tal constatação, por si só, já justificaria a necessidade urgente de investimentos na educação prisional.

Nas políticas públicas que vinculam educação e cárcere, encontra-se o Pronatec Prisional, voltado a detentos em regime fechado, semiaberto e aberto, bem como egressos. Neste sentido, a oferta de cursos profissionalizantes para presidiários surge como forma de diminuição do tempo de cumprimento da pena (o que antes só acontecia por meio de trabalho) e como preparação para o mercado de trabalho na etapa de ressocialização.

O Pronatec - Sistema Prisional foi instituído em 2013, mediante acordo de cooperação celebrado entre os Ministérios da Justiça e da Educação, visando a oferta de vagas exclusivas e gratuitas aos apenados e assim, atendendo a uma demanda significativa de cursos profissionalizantes em um ambiente muito restrito.

A capacitação profissional, embora não promova elevação de escolaridade, permanece sendo a forma mais imediata de capacitação e inserção no mercado de trabalho. Assim, no ambiente prisional, além de cursos EJA, tem sido mais frequente a realização de cursos de formação inicial e continuada (FIC), que duram de 3 a 4 meses e que exigem ensino fundamental incompleto. 
No âmbito do Pronatec a pactuação de vagas ocorre com base em um "mapa de demandas", onde é possível verificar quais os setores mais carentes de mão-de-obra em uma determinada localidade ou na região. Em relação aos cursos ofertados nos presídios, é a mesma lógica: não basta a oferta aleatória de cursos, pois há que se ter em mente que o preso sairá em liberdade em algum momento de sua vida e terá mais chances de reinserção se estiver capacitado para os nichos de mercado. Neste sentido, na percepção de Nascimento (2009), os programas de formação devem ser feitos de acordo com as necessidades da população prisional e do mercado de trabalho da área, e devem englobar "a formação de competências sociais que permitam aos reclusos lidar melhor com o seu quotidiano e permitir preparar o seu regresso à sociedade e a formação de competências individuais" (p. 27).

O IFFar, até então só havia atuado no sistema prisional a partir de ações pontuais no âmbito do Programa Nacional de Integração da Educação Profissional com a Educação Básica na Modalidade de Educação de Jovens e Adultos - PROEJA, nos municípios de São Borja, Santa Rosa, Alegrete, Jaguari.

A inserção do IFFar no segmento prisional, via Pronatec, iniciou de forma experimental com a oferta de duas turmas no município de Júlio de Castilhos, em momentos distintos (2015 e 2016), vindo a formar aproximadamente 30 alunos de um total de 40 matriculados.

A participação do campus Júlio de Castilhos no Pronatec sempre foi muito expressiva, ao considerarmos a quantidade de vagas pactuadas e a constante oferta de cursos fora de sede, ou seja, é a instituição indo até onde está a demanda e não se restringindo apenas ao campus. No caso do Prisional, ocorreu a partir da oferta de dois cursos FIC, em 2015 foram 20 alunos matriculados no curso de Eletricista Instalador Predial de Baixa Tensão e em 2016, mais 20 alunos para o curso de Pintor de Obras Imobiliárias, vindo a concluir quinze em cada turma (Sistec, 2017).

\section{METODOLOGIA}

\subsection{QueSTÕES DE INVESTIGAÇ̃̃O}

A pesquisa visou coletar informações sobre a oferta de cursos do Pronatec no âmbito do sistema prisional, dentro da perspectiva dos vários atores envolvidos no Programa, com vistas a obter subsídios para averiguar se a ação foi exitosa e se de fato colaborou para a formação e ressocialização dos beneficiados do Programa.

O estudo traduz uma "pesquisadiagnóstico", com a recolha de dados que se complementaram, ao contemplar tanto a quantificação dos dados como a qualificação dos fatos observados no transcorrer da pesquisa, de modo a viabilizar um cruzamento das informações coletadas e assim, corroborando para uma interpretação mais abrangente da realidade posta.

O Estudo de Caso apresentou-se como a forma mais adequada para buscar as respostas ao problema, pois in casu, estava-se diante de um fenômeno em seu ambiente real, demandando uma análise minuciosa do caso e suprindo a necessidade de estudar com maior precisão o contexto em que o público-alvo estava inserido. Pretendeu-se, assim, uma análise crítica baseada nos relatos de experiências trazidos pelos sujeitos envolvidos no processo de implantação e execução de cursos no ambiente prisional, a partir das demandas atendidas pelo Pronatec no município de Júlio de Castilhos.

\subsection{INSTRUMENTOS DE RECOLHA DOS DADOS}

A atuação no Pronatec Prisional integra a figura do educador e do educando, envolve também a Coordenação do programa e equipe, bem como a Direção do estabelecimento prisional, composta por agentes e técnicos penitenciários, ou seja, foram vários os segmentos envolvidos em prol da formação de sujeitos privados de liberdade. O estudo empírico transcorreu a partir de pesquisa bibliográfica, documental, entrevistas e questionários. 
Em relação aos apenados, procurou-se traçar o perfil deste público, averiguar a situação deles e suas pretensões após adquirirem liberdade, ainda que provisória, aplicando um questionário simples e com perguntas diretas e respostas de múltipla escolha, que facilitou o acesso às informações pretendidas.

Em julho de 2018, foi aplicado o questionário para os ex-alunos apenados, mediante prévia autorização pela Administração do estabelecimento prisional e pela Susepe.

Pretendeu-se igualmente resgatar informações sobre as tratativas realizadas no âmbito do Pronatec e as intenções futuras de novos projetos do Pejuli em parceria com o IFFar, bem como traçar um cenário da situação dos apenados que participaram do programa, para posteriormente confrontar com as informações obtidas por eles, através de entrevista semiestruturada e individual.

A entrevista semiestruturada visou atingir uma verificação dos saberes já adquiridos nos planos: cultural, cognitivo, motivacional e conjuntural, assim como busca um maior aprofundamento na temática estudada, no caso, a educação no sistema prisional, sem, obviamente, esgotar o assunto.

\subsection{AMOSTRAS}

Quanto aos sujeitos da pesquisa, uma parte foi entrevistada e os demais responderam um questionário. Foram entrevistados onze profissionais, o que equivale a $65 \%$ da estimativa inicial, e nove apenados responderam ao questionário, totalizando dezenove pessoas, uma vez que um dos apenados contribuiu com ambas as ferramentas. Muito dessa redução no número de entrevistados se deu pela dificuldade em localizar e contatar os ex-professores: todos foram convidados por email, mas apenas dois responderam e contribuíram para a pesquisa.

De um total de quarenta matriculados, frequentaram e concluíram a formação vinte e nove apenados. Destes, seis participaram dos dois cursos, obtendo-se somente vinte e três indivíduos aptos a responder o questionário. Considerando que dez deles se disponibilizaram a contribuir para a pesquisa, entre entrevistas e questionários, obteve-se $43,48 \%$ de adesão.

No que diz respeito à Coordenação do Pronatec, servidores penitenciários e professores, as entrevistas foram realizadas no Presídio, no IFFar (Campus Júlio de Castilhos e Reitoria) e em locais públicos (exprofessores), em datas previamente agendadas, conforme disponibilidade dos entrevistados.

Desta fase resultaram aproximadamente três horas de áudio, uma média de dezesseis minutos para cada entrevistado. Os áudios das gravações permitiram a transcrição fidedigna das entrevistas. Tais arquivos de áudio e respectivas transcrições, as autorizações de uso de imagem e depoimentos, bem como os TCLE's assinados, estão sob a guarda da pesquisadora.

Atendendo ao previsto no projeto, dentre os entrevistados, foi possível colher depoimentos de um ex-aluno apenado que está cumprindo pena em regime fechado e de outro que está no regime semiaberto.

Cumpre salientar que, com o intuito de preservar a identidade dos participantes, estes foram designados com letras, de forma aleatória, independente da ordem de participação na pesquisa, e assim foram tratados no decorrer da análise.

Figura 01-Sujeitos da pesquisa e a relação com os métodos de investigação

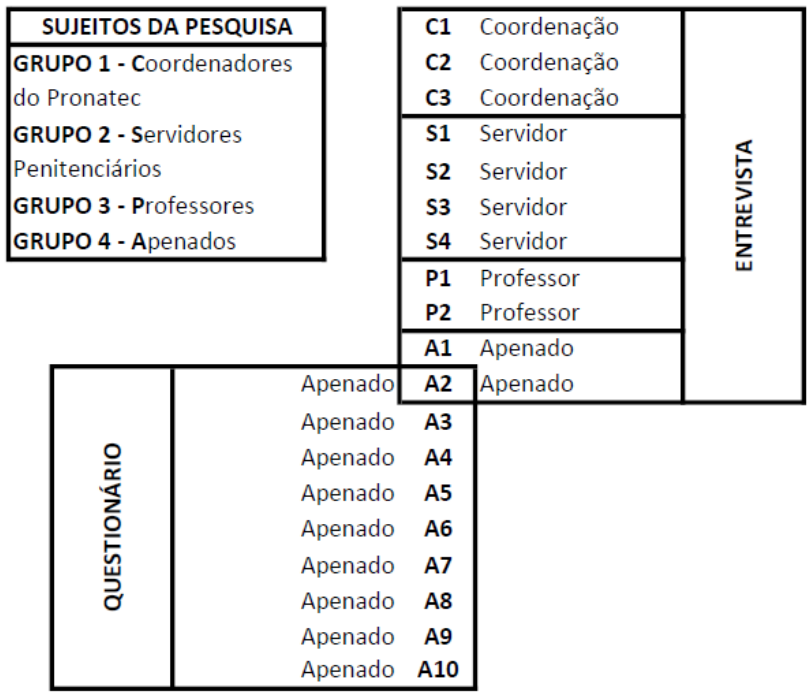

Fonte: elaborado pelos investigadores 


\subsection{QUESTÕES ÉTICAS}

O projeto de pesquisa bem como os roteiros de inquérito e questionário foram previamente submetidos à aprovação de Comitê de Ética em Pesquisa do IFFar e do Grupo de Trabalho em Ética e Pesquisas nos Estabelecimentos Prisionais da Susepe.

Ao longo do processo de recolha de dados, os investigadores explicaram o estudo a todos os participantes, garantindo a confidencialidade e o anonimato das respostas, bem como a não obrigação de responder ou, respondendo, a possibilidade de não responder a qualquer pergunta quando se sentisse despreparado ou desconfortável.

Todos os respondentes receberam prévios esclarecimentos acerca dos instrumentos a serem aplicados e sobre o inteiro teor do Termo de consentimento livre e esclarecido - TCLE, bem como o Termo de autorização de uso de imagem e depoimentos, os quais foram assinados pelas partes, em duas vias.

\subsection{ANÁLISE DOS DADOS}

A partir da análise de conteúdo e dos dados coletados à luz do recorte teórico e das categorias utilizadas para a apreciação, realizou-se uma sistematização geral, com base na triangulação de informações, que convergiram para observações e conclusões.

Como a pesquisa versou sobre uma temática que envolveu tanto dados quantitativos quanto qualitativos, a triangulação dos dados proporcionou um resultado mais confiável, pautado na análise estatística e de conteúdo, onde permitiu à pesquisadora constatar eventuais discrepâncias nos assuntos abordados, os quais foram percebidos sob diferentes perspectivas (a do preso, a do servidor penitenciário, a do educador e a administração escolar). Tratava-se de uma forma de manejar as informações de forma ampla, mas trazendo coerência e coesão na pesquisa empírica. Neste caso, os resultados obtidos nas mais variadas metodologias não se contrariam, eles se complementam.

\section{RESULTADOS}

Ao compilar as respostas obtidas nos questionários e nas entrevistas, com base no conjunto de perguntas dirigidas a cada segmento (servidores penitenciários, coordenadores Pronatec, professores e egressos), foi possível agrupar os resultados em três grandes categorias, a seguir detalhadas.

\subsection{SOBRE A MOTIVAÇÃO PARA OFERTA E CONDI- Ç̃̃ES DE FUNCIONAMENTO DOS CURSOS NO ÂMBITO do Pronatec PRIsional}

A parceira institucional estabelecida entre IFFar e o Pejuli bem como a necessidade de atendimento da demanda por assistência educacional foi relatada de forma consensual pelos Coordenadores do Pronatec e servidores penitenciários entrevistados. Conforme reportado por um servidor do Pejuli, existe a obrigação de fomentar atividades educacionais dentro do estabelecimento prisional, mas não bastaria a oferta de cursos de forma aleatória, para efeito de mero cumprimento da Lei de Execução Penal. Diante da realidade estudada, necessitariam cursos que exigissem ensino fundamental incompleto e que de fato propiciassem fácil colocação no mercado de trabalho, como era o caso dos cursos de eletricista de baixa tensão e pintor de obras imobiliárias.

O processo de implantação dos referidos cursos se deu a partir de adaptações mínimas/ básicas que não alterassem sobremaneira a rotina do presídio e que transcorreram de forma tranquila, pois houve cooperação de todas as partes envolvidas. De acordo com um dos servidores penitenciários entrevistados, "a questão do Pronatec, dos cursos, começaram a circular na rotina do presídio, como algo comum, tanto pros guardas quanto pros presos. (...) a gente tinha alguns receios, mas que foram superados no decorrer do caminho." (S3)

O IFFar fez as aquisições de material de consumo, tintas, etc. necessários para as aulas, e a Administração do Pejuli disponibilizou local para 
servir como sala de aula, bem como posteriormente facilitou o acesso às galerias para aulas práticas, sempre conciliando com as questões de segurança.

Algumas dificuldades e obstáculos foram relatados pelos servidores penitenciários, especialmente no que diz respeito às solenidades de formatura, tendo em vista a questão da mobilização de um grande número de agentes e de questões de segurança que viabilizassem a escolta e acompanhamento dos formandos até o local do ato solene.

O Sistec também foi mencionado como dificuldade, do ponto de vista procedimental, tanto por parte dos servidores penitenciários quanto pelas Coordenações Geral e Local do Pronatec. Tratase de uma ferramenta indispensável para o registro das matrículas, frequências, etc., vindo a disponibilizar indicativos importantes para a gestão escolar. Na prática, tal ferramenta costumava ficar inoperante com frequência.

Já os professores, ao serem inquiridos sobre condições exigidas para as aulas serem ministradas em um ambiente prisional, relataram a necessidade de pequenos ajustes na preparação e metodologia das aulas práticas, respeitando as regras de segurança, mas nada que pudesse interferir no desempenho do curso.

Do ponto de vista dos servidores do Pejuli, foi criado um ambiente propício às aulas, permitindo que os professores se adaptassem com facilidade a um ambiente até então desconhecido pela maioria deles, mas conforme um dos relatos, "foi uma grata surpresa para eles, constatar que eles foram muito acolhidos aqui, tinha... sempre teve muito respeito com os professores também. Nós não temos nenhum relato de qualquer tipo de situação, de constrangimento ou qualquer coisa que fosse..." (S1)

Ainda sobre o quesito organização pedagógica, as Coordenadoras entrevistadas explicitaram de forma clara e objetiva o papel de cada parte envolvida: governo, instituição de ensino, alunos e o estabelecimento prisional demandante das vagas. Ressaltaram, ainda, que a maior parte do tempo a Coordenação local do Pronatec teve uma equipe reduzida, mas nem isso inviabilizou o funci- onamento dos cursos. Relataram, ainda, alguns obstáculos enfrentados e dificuldades financeiras devido ao corte de orçamento, mas que foram superadas com a contrapartida do campus e a mobilização de colegas.

\subsection{SOBRE AS ESPECIFICIDADES DO PÚBLICO A SER beneficiado pelo Pronatec Prisional}

Os sujeitos entrevistados, em especial os servidores penitenciários, trouxeram relatos muito importantes sobre a situação dos alunos e suas especificidades enquanto apenados do regime fechado e as suas intenções em relação ao Pronatec. Tais informações foram confrontadas com as respostas dos questionários dos apenados, propiciando, assim, as constatações a seguir expostas.

De acordo com a Direção do Pejuli, estão privadas de liberdade aproximadamente 100 pessoas, exclusivamente do sexo masculino, em regime aberto, semiaberto, fechado e prisão civil, sendo provisórios e condenados, bem como primários e reincidentes.

O perfil socioeconômico destes apenados foi retratado com base na faixa etária, cor da pele, nível de escolaridade, sexo, grau de periculosidade, etc. De acordo com um dos servidores entrevistados, os apenados do Pejuli são exclusivamente homens, jovens, considerados de baixa periculosidade e com pouca instrução (escolaridade), a maioria apenas com ensino fundamental incompleto.

Partindo destas informações iniciais e da aplicação dos questionários foi possível traçar o perfil do público estudado, que representa aproximadamente $10 \%$ do total de apenados do Pejuli. Este grupo de respondentes é composto por sujeitos do sexo masculino, a maioria com idade na faixa de 40 a 49 anos (67\%), mais da metade se declara branco (56\%), casados $(44 \%)$ e com ensino fundamental completo (44\%).

Antes de suas condenações, todos os apenados exerciam atividades remuneradas, sendo que a maioria tinha profissões autônomas ou voltadas ao setor de serviços, como por exemplo, mo- 
torista, cabelereiro, serviços gerais, etc. Dois deles eram agricultores, ocupação vinculada à principal fonte de renda do município, que é essencialmente agrícola.

Cerca de metade deles possui pena entre 06 e 10 anos (44\%) ou excedem os 15 anos (33\%). A maioria nunca havia cumprido pena antes (56\%) e quase dois terços deles sairão em liberdade em até 5 anos. Quase todos trabalham no presídio e terão parte de sua pena remida pelo trabalho. Apenas um deles informou não trabalhar.

O tempo da pena impactou no critério de seleção. Conforme exposto pelos servidores penitenciários entrevistados, a disponibilidade para participar dos cursos até o final, baseando-se no tempo de pena que ainda faltava ser cumprido, foi critério essencial para a escolha dos 20 alunos de cada curso ofertado, tentando evitar desistências durante os cursos: "a gente busca dar oportunidade pra todos. Todos estão na mesma condição, cumprindo suas penas", ressalvando, todavia, que "os presos provisórios acabaram não tendo preferência nos cursos porque eram cursos a médio prazo, então precisavam ficar um tempo." (S3)

Entretanto, apesar desta precaução, os Coordenadores entrevistados relataram que a taxa de evasão se deu em torno de $25 \%$, aproximadamente 5 alunos por turma, sendo que grande parte deste quantitativo representa casos de transferência ou progressão de regime, ou seja, não eram desistências voluntárias.

Além do perfil dos apenados, o questionário trouxe perguntas voltadas à experiência deles como alunos. Em relação aos cursos, a maioria realizou um (44\%) ou dois (44\%) cursos profissionalizantes dentro do presídio. Eles avaliam que a quantidade de cursos ofertados no Pejuli varia de boa, muito boa ou excelente. Mais da metade deles, ou seja: $56 \%$, consideram como excelente em termos de qualidade dos cursos.

Sobre a intenção dos alunos ao se matricularem nos cursos, a maioria dos profissionais entrevistados relatou ter percebido que alguns alunos tinham o intento inicial de terem parte de seu tempo de pena reduzido, mas que aos poucos foram se interessando pelo curso e pelas oportuni- dades advindas da formação, passando a ter como objetivo a efetiva qualificação e preparação para o mercado de trabalho.

Tal relato veio ao encontro das respostas apuradas nos questionários, pois todos os apenados declararam estar cientes de que o estudo também proporciona a remição de pena, que participar de cursos profissionalizantes dentro da prisão facilita a reinserção no mercado de trabalho e que ter frequentado tais cursos gerou mudanças de comportamento ou gerou expectativas para seu futuro. Relatam os apenados entrevistados que ambos tiveram, em média, 15 dias de remição de pena em cada curso concluído.

Questionados sobre eventuais dificuldades enfrentadas durante os cursos, o fato de alguns não saberem ler e escrever direito, tendo que ter auxílio dos professores para acompanhar o restante da turma, foi um dos apontamentos verificados. Tal informação procede, pois do total de apenados que responderam ao questionário, 3 deles, ou seja, 33\% declararam não saber ler ou escrever direito. Outras dificuldades foram apontadas por $45 \%$ deles, como o fato de estarem trabalhando no presídio durante o dia e por tal motivo não terem conseguido se inscrever em cursos, ensejando a oferta de cursos noturnos, por exemplo.

De fato algumas dificuldades deste tipo foram reportadas pelos professores. Durante as aulas, determinadas necessidades foram constatadas, especialmente em relação ao conhecimento de matemática, mas nem por isso ensejou adaptações nos projetos-pedagógicos dos cursos. Partiu dos professores entrevistados a iniciativa de propiciar reforço em fundamentos da disciplina e o uso de calculadoras, por exemplo.

Ainda sobre os apenados, foi consenso entre os entrevistados que mudanças comportamentais e/ou motivacionais foram detectadas, especialmente com base em relatos de servidores do Pejuli: "as mudanças comportamentais eram claras, isso constatou-se... isso, quando tu oferta algo eles começam a se empoderar a partir daquele lugar de aluno. Acho que isso é bem interessante de pensar, neste processo de educação, porque ele no- 
meia o sujeito a partir do outro lugar, independente do espaço, pode ser uma escola." (S3)

Neste quesito, um dos professores entrevistados observou que: "90\% estava com a cabeça muito aberta para aprender, é algo diferente, eles tinham a concentração melhor do que muitos dos meus colegas de graduação! (...) faziam perguntas que muitas vezes nós, como alunos, não iríamos fazer. Então eles tinham interesse, queriam aprender... (...) Eu sentia neles era uma empolgação." (P1)

Cumpre também destacar a satisfação reportada pelos professores ao ministrarem aulas para apenados, pois os professores entrevistados relataram que havia expectativa tanto da parte deles quanto dos alunos, mas também uma certa apreensão, tendo em vista se tratar de um ambiente peculiar e um público restrito, que até então não tinham tido contato. Apesar disso, disseram que a relação professor-aluno foi muito satisfatória: "Acredito muito que o espaço da sala de aula é espaço democrático, né, que todo mundo tem que ter pertencimento naquilo ali e construir o conhecimento juntos (...) pra mim eles foram, eram, são meus alunos da mesma forma que os alunos da graduação, né, dos outros lugares que eu tive. E... e... foi bem legal, tinha bastante retorno." (P2)

De fato a relação com os professores foi classificada pelos apenados entrevistados como boa e excelente. Um deles enfatizou: "Excelente. Todos brincavam bem com nós, explicavam bem as matérias, se a gente tinha uma dificuldade eles vinham até a mesa ali e explicavam de novo. Tudo, material didático eles auxiliavam nós também, tudo excelente." (A2).

Dentre as questões subjetivas que constavam ao final do questionário, uma delas perguntava aos apenados quais cursos fizeram ou gostariam de fazer e que achavam importantes para sua vida profissional. Cursos como eletrônica, mecânica, eletricista de alta tensão ou outros na área de engenharia (leia-se: infraestrutura, no caso dos FIC's) foram citados.

A partir disto é possível inferir que os cursos até então ofertados atenderam aos anseios dos apenados e de fato estão vinculados às áreas que demandam mais mão-de-obra qualificada, o que pode ser um indicativo de que as escolhas de cursos foram acertadas, vindo a atender uma demanda crescente.

No entanto, ao questionar os servidores penitenciários em relação à situação dos apenados egressos do Pronatec Prisional, constatou-se não haver um acompanhamento efetivo, seja por falta de estrutura, seja pela reduzido número de servidores disponíveis, restando-lhes informações extraoficiais: "Algumas informações que nós temos, de alguém que conhece, enfim, mas muito superficial, assim. O que é uma demanda... seria bem importante." (S1)

Por fim, foi perguntado aos apenados se eles concordavam que a educação poderia transformar a vida de um detento, a resposta afirmativa foi unânime. Respostas como "a educação leva a oportunidades como emprego, conhecimento", "pode sim transformar para melhor. Porque aprendemos muito", "a educação é muito importante para nós e para o futuro de nossos filhos. Hoje tudo envolve educação eu, na minha opinião, acho muito importante" se destacaram entre as demais e conduzem ao entendimento de que a oferta de cursos no Presídio de Júlio de Castilhos foi muito bem recebida pelos apenados e os tornaram mais esperançosos de que haverá uma nova chance para eles enquanto indivíduos, em sociedade.

\subsection{SOBRE PERSPECTIVAS FUTURAS E OUTROS PONTOS A CONSIDERAR}

A indagação sobre perspectivas futuras em relação ao Pronatec foram direcionadas às Coordenações do Programa e aos servidores penitenciários, no entanto, cientes de que o referido programa está com outro enfoque e com cada vez menos oferta de vagas, tendo em vista os cortes orçamentários, os entrevistados expuseram outras expectativas em relação à parceria do IFFar com o Pejuli.

Recordaram que algumas oficinas e projetos de extensão já haviam sido executados por 
meio desta parceria, sendo a oferta de curso de microempreendedor individual a ação mais recente, que nasceu da mobilização dos professores do eixo Gestão e Negócios do Campus Júlio de CastiIhos. Embora ofertado fora do Pronatec, foi um curso desenvolvido para dar continuidade à profissionalização dos apenados que se formaram especialmente nos cursos de eletricista e pintor: "Sou um aluno' (...) isso é revolucionário na vida de uma pessoa. Se identificar a partir de outro lugar que não seja só lugar do preso, que cometeu um delito. (...) O micro empreendedor é isso, empreender a partir do que tu já sabe, coisas que tu nem reconhece que sabe..." (S3)

De fato todos os entrevistados acreditam que tiveram êxito nas ações desenvolvidas no âmbito do programa e expuseram a satisfação de terem contribuído na formação de pessoas privadas de liberdade. Os professores, por exemplo, classificaram como "gratificante", "empoderadora", sua experiência com os apenados nos cursos do Pronatec Prisional. Relata um deles: “(...) eu tenho certeza que enquanto os professores estavam lá, enquanto o curso tava acontecendo, eles tiveram oportunidade, no mínimo, de repensar a vida deles, tanto quanto pessoas, quanto a parte profissional mesmo, de enxergar... que... que eles estavam tendo uma chance." (P2)

Organização logística, o aparato policial, a exposição dos presos, a possibilidade de constrangimento ao chegarem algemados, a presença da mídia, etc... Tudo isto foi levado em conta no momento em que os entrevistados se mobilizaram para propiciar a solenidade de formatura para os apenados concluintes e nem por isso deixaram de propiciar esta oportunidade à eles. Foi um esforço coletivo.

\section{DISCUSSÃO E CONSIDERAÇÕES FINAIS}

A investigação que balizou o presente estudo de caso sobre o Pronatec Prisional, enquanto política pública na área da educação, veio confirmar que o sistema prisional carece de maior atenção das autoridades e da comunidade em geral.
Enquanto isso não suceder, a assistência educacional não pode cumprir o seu papel de se constituir num fator relevante para a ressocialização de sujeitos privados de liberdade.

O estudo foi realizado de forma a cumprir o cronograma proposto, mas ciente da repercussão do fator tempo: o pequeno período transcorrido entre a oferta de cursos e o estudo empírico realizado, bem como o longo tempo que tende a levar para que o preso readquira a liberdade e, sobretudo, consiga tornar-se um indivíduo atuante e ressocializado, voltando a ser um sujeito de direitos e obrigações, como qualquer outra pessoa.

Em relação ao objetivo proposto de averiguar a situação atual dos apenados, constatou-se que um número significativo dos apenados possuía efetivo interesse em capacitações, em trabalho interno, ou ambos, visando se ocuparem durante o dia e, sobretudo, obterem a remição de dias da pena. A intenção persiste, tanto é que ao responderem o questionário, quase todos indicaram cursos de seu interesse e elogiaram os cursos até então ofertados.

Desta análise também foi possível identificar um grupo muito participativo dentro da massa carcerária daquele estabelecimento, que se envolveram nos projetos ofertados, participaram dos cursos, trabalharam... inclusive, alguns reclamaram que a oferta de cursos ocorreu em horário incompatível com o período de trabalho, razão pela qual alguns não conseguiram conciliar estudo e trabalho.

Um dos objetivos traçados foi realizar um levantamento da situação dos ex-alunos, especificamente sobre índices de evasão, reincidência e empregabilidade. Neste ponto há uma série de fatores que foram considerados.

A evasão no ambiente prisional, por exemplo, não pode ser encarada como a típica evasão que ocorre em turmas regulares, objeto de atendimento pelos programas de permanência e êxito, como existe no IFFar. Ela decorre de transferências e progressões de regime, no caso, do fechado para o semiaberto.

Assim, uma vez que o curso ofertado visa atender demandas exclusivas do sistema prisional 
em regime fechado, quando o preso progride para o semiaberto, ele deixa de preencher os requisitos intrínsecos da oferta. Ou seja, ele não desiste de forma espontânea. Ele deixa de frequentar o curso porque passa para um regime inconciliável com os requisitos da modalidade ofertada.

O mesmo sucede com as transferências: constatou-se que não houve desistência voluntária de alunos-apenados, mas surgiram condições importantes para as suas vidas pregressas que eram incompatíveis com a manutenção no(s) curso(s). Conforme relataram alguns entrevistados, o preso que não tem interesse em estudar ou trabalhar, nem se candidata às vagas. Em contrapartida, os que são participativos, envolvem-se em todas as oportunidades que surgem, sempre tendo em mente que, no momento em que estão ocupando seu tempo com atividades educativas ou laborativas, deixam o ócio de lado, obtendo a impressão de que o tempo passa mais rápido.

A reincidência já é um ponto que demandou muita atenção, pois durante a pesquisa não foi possível descobrir indicativos precisos do quantitativo de presos do Pejuli que voltaram a cometer os crimes. Consultando o site da Susepe foi possível encontrar uma estimativa no RS de que $71,4 \%$ de homens, $61,6 \%$ de mulheres, ou seja, aproximadamente $70,9 \%$ da população carcerária reincide (Susepe, 2018).

Considerando esta situação, também não foi possível verificar a situação dos alunos egressos dos cursos analisados, por não existir um acompanhamento neste sentido e porque o quantitativo de egressos que saíram em liberdade era reduzido.

Outro objetivo do estudo consistiu em buscar subsídios para avaliação das questões administrativas e pedagógicas necessárias à efetividade do programa, com base nas experiências relatadas. Neste sentido, foi possível constatar que, de forma geral, a gestão educacional necessária para a oferta de cursos do Programa foi extremamente satisfatória e exitosa, apesar das condições alegadas (equipe reduzida e corte de orçamento). Tal resultado positivo foi corroborado por todos os entrevistados.
Denotou-se pelas falas dos entrevistados envolvidos que os cursos ofertados via Pronatec Prisional, à primeira vista, pareciam difíceis de executar, mas ao final foram os mais profícuos, pois os alunos estavam matriculados e frequentando porque tinham interesse, diferente da realidade dos demais alunos do Pronatec, que em sua maioria frequentam os cursos principalmente visando a percepção do auxílio financeiro proporcionado pelo Programa.

Diante de todas as ponderações realizadas a partir da análise dos objetivos supramencionados, é possível apresentar um conjunto de considerações acerca de necessidades e melhorias importantes como:

- maior aporte de recursos orçamentários e financeiros por parte do Governo Federal, que proporcionem uma oferta contínua de cursos de qualificação para públicos carentes de inclusão social, permitindo que a escola vá até o aluno quando for preciso, como é o caso dos apenados;

- maior investimento em segurança, permitindo uma melhor estruturação dos estabelecimentos prisionais e o aumento do efetivo de servidores penitenciários, a fim de viabilizar, por exemplo, o acompanhamento dos egressos e facilitar o fomento de indicadores mais precisos para o sistema prisional, da forma como já vem ocorrendo com os censos penitenciários e assim, servirem de base para a manutenção de políticas públicas neste segmento;

- fortalecimento de ações de extensão aproximando o IFFar da comunidade em geral e auxiliando no desenvolvimento local;

- manutenção da parceria com o Presídio de Júlio de Castilhos, ofertando cursos que se complementem, ou seja, garantindo o aproveitamento contínuo e articulado dos estudos, como é o caso dos cursos ofertados no Pejuli, onde o curso de microempreendedor individual, do Eixo Gestão e Negócios, por exemplo, que apesar de ofertado fora do Pronatec, complementa os saberes adquiridos como eletricista ou pintor, preparando os egressos para o mercado de trabalho com maior potencial de empregabilidade; 
- fomento de um programa de acompanhamento de egressos no âmbito do Pronatec, da mesma forma como vem ocorrendo com os alunos dos demais cursos do IFFar, etc.

A partir destas ponderações foi possível aferir que as políticas públicas vinculadas à educação em ambientes prisionais são imprescindíveis para que indivíduos privados de liberdade estejam preparados para um recomeço em sociedade. 0 presente estudo só veio a corroborar esta necessidade e a constatação de uma receptividade positiva em relação a este tipo de iniciativa, por parte dos apenados.

Constatou-se, por conseguinte, que a oferta educacional existente no sistema prisional ocorre em número insuficiente para atender à demanda: esta não acompanha o crescimento da população carcerária. Disto surge a necessidade de um maior aporte de investimentos governamentais que fomentem ações educacionais no ambiente prisional, por meio de uma educação inclusiva que contemple um maior número de apenados e que, de fato, prepare-os para uma efetiva ressocialização.

Em suma, concluiu-se que a atuação das instituições de ensino é fundamental para o êxito destas propostas. Por meio de uma gestão articulada, a escola exerce o seu papel transformador na vida das pessoas e da comunidade local, buscando atender demandas pontuais e assim, suprir carências da região de sua abrangência. Prepondera, desta forma, a necessidade de manutenção de ações que conciliem os propósitos das escolas com os interesses de demandantes de ofertas exclusivas, como até então vinha ocorrendo no Pronatec Prisional.

\section{REFERÊNCIAS}

ARAÚJO, M. A. D. de; BORGES, D. F. Globalização e Mercado de Trabalho: educação e empregabilidade. Organizações \& Sociedade, v. 6, n. $17,2000$.
BRASIL. Constituição da República Federativa do Brasil, de 12 de outubro de 1988. Brasília: Diário Oficial da União, 1988.

BRASIL. Decreto no 7.626, de 30 de novembro de 2011. Institui o Plano Estratégico de Educação no âmbito do Sistema Prisional. Brasília: Diário Oficial da União, 2011.

BRASIL. Lei no 7.210, de 11 de julho de 1984. Lei de Execução Penal. Brasília: Diário Oficial da União, 1984.

BRASIL. Lei no 9.394, de 20 de dezembro de 1996. Lei de Diretrizes e Bases da Educação Nacional. Brasília: Diário Oficial da União, 1996.

BRASIL. Lei no 10.172, de 09 de janeiro de 2001. Plano Nacional de Educação. Brasília: Diário Oficial da União, 2001.

BRASIL. Lei $n$ ㅇ 11.741, de 16 de julho de 2008. Altera dispositivos da Lei no 9.394, de 20 de dezembro de 1996. Brasília: Diário Oficial da União, 2008.

BRASIL. Lei $\mathrm{n} 0$ 11.892, de 30 de dezembro de 2008. Institui a Rede Federal de Educação Profissional, Científica e Tecnológica. Brasília: Diário Oficial da União, 2008.

BRASIL. Lei no 12.245, de 24 de maio de 2010. Altera o art. 83 da Lei no 7.210, de 11 de julho de 1984 - Lei de Execução Penal, para autorizar a instalação de salas de aulas nos presídios. Brasília: Diário Oficial da União, 2010.

BRASIL. Lei no 12.433, de 29 de junho de 2011. Altera a Lei no 7.210, de 11 de julho de 1984 (Lei de Execução Penal), para dispor sobre a remição de parte do tempo de execução da pena por estudo ou por trabalho. Brasília: Diário Oficial da União, 2011 a.

BRASIL. Lei no 12.513, de 26 de outubro de 2011. Institui o Programa Nacional de Acesso ao Ensino Técnico e Emprego (Pronatec). Brasília: Diário Oficial da União, 2011b.

JULIÃO. E. F. "Escola na ou da prisão?" Cad. Cedes, Campinas, v.36, n. 98, p-25-42, jan-abr, 2016.

Disponível em http://www.scielo.br/pdf/ccedes/ 
v36n98/1678-7110-ccedes-36-98-00025.pdf. Acesso em: 21 fev. 2018.

MINISTÉRIO DA EDUCAÇÃO. Resolução no 4. Dispõe sobre as Diretrizes Operacionais Nacionais para a remição de pena pelo estudo de pessoas em privação de liberdade nos estabelecimentos penais do sistema prisional brasileiro. Ed. 102, seção 1, p. 16, Brasília: Diário Oficial da União, 2016.

MINISTÉRIO DA JUSTIÇA. Levantamento Nacional de Informações Penitenciárias (Infopen). Brasília/ DF, 2017. Disponível em https://www.justica. gov.br/news/ha-726-712-pessoas-presas-nobrasil/relatorio_2016_junho.pdf. Acesso em: 08 out. 2017.
NASCIMENTO, A. M. S. A Formação Profissional nas Prisões: o curso de Jardinagem EFA B3. Dissertação de Mestrado, FPCEUL, Lisboa, Portugal, 2009. Disponível em http://repositorio. ul.pt/ handle/10451/920. Acesso em: 10 jun. 2018.

SISTEC. Sistema Nacional de Informações da Educação Profissional e Tecnológica. Ministério da Educação. Brasília/DF, 2017. Disponível em http:// sistec.mec.gov.br/. Acesso em: 07 ago. 2017.

SUSEPE. Mapa Prisional. Porto Alegre, RS, 2018. Disponível em http://www.susepe.rs.gov.br. Acesso em: 10 mar. 2018 e 20 nov. 2018. 